\title{
Analysis of toxic, antidiabetic and antioxidant potential of Bambusa balcooa Roxb. leaf extracts in alloxan-induced diabetic rats
}

\author{
Arvind Kumar Goyal ${ }^{1}$ - Sushil Kumar Middha ${ }^{2}$ Talambedu Usha ${ }^{3}$ • \\ Arnab Sen ${ }^{4}$
}

Received: 9 June 2016/Accepted: 14 February 2017/Published online: 31 May 2017

(C) Springer-Verlag Berlin Heidelberg 2017

\begin{abstract}
Bambusa balcooa (Poaceae) is native to India and has been used traditionally by the tribes of Northeast India to treat diabetes. The present investigation was aimed to evaluate the toxicity, anti-diabetic activity along with in vitro antioxidant activity of the leaf of $B$. balcooa in alloxan-induced diabetic rats and also identify active compounds by using HPLC. The acute toxicity test of aqueous extract of $B$. balcooa leaf revealed that the median lethal dose $\left(\mathrm{LD}_{50}\right)$ of $B$. balcooa aqueous extract (BAQE) was $5.18 \mathrm{~g} / \mathrm{kg}$ body weight in mice. Administration of BAQE at 100 and $200 \mathrm{mg} / \mathrm{kg}$ in alloxan-induced diabetic rats showed significant reduction in fasting blood glucose and glycated hemoglobin while plasma insulin level was elevated compared to diabetic control. Both the doses were effective when compared to diabetic glibenclamide rats. The BAQE treated diabetic rats showed significant increase in the endogenous antioxidant enzymes superoxide dismutase, glutathione peroxidase and decrease in malondialdehyde levels. HPLC analysis of BAQE showed the presence of rutin, gallic acid and $\beta$ sitosterol. Thus, it can be inferred from this study that $\mathrm{BAQE}$ possess antidiabetic
\end{abstract}

Arvind Kumar Goyal

arvindgoyal210883@gmail.com

1 Bamboo Technology, Department of Biotechnology, Bodoland University, Kokrajhar 783370, Assam, India

2 Department of Biotechnology, PG (Science) Research Centre, Maharani Lakshmi Ammanni College for Women, Bengaluru 560012, Karnataka, India

3 Department of Biochemistry, Maharani Lakshmi Ammanni College for Women, Bengaluru 560012, Karnataka, India

4 Molecular Genetics Laboratory, Department of Botany, University of North Bengal, Siliguri 734013, West Bengal, India and in vivo antioxidant activity. The overall activity might be possibly due to the presence of potential antioxidants.

Keywords Bambusa balcooa - Antioxidants - Diabetes · Toxicology $\cdot$ Flavonoids $\cdot$ Polyphenols

\section{Introduction}

Tropical medicines are the main stay of therapy for most of the patients in developing countries. Diabetes mellitus (DM) is prevalent among almost 200 million people worldwide, which is thought to increase exponentially to 300 million in the next two decades, type 2 being more common (Choi et al. 2008). Increased oxidative stress and exhausted antioxidant defences are mainly responsible for the chronic hyperglycemia, which further leads to dysfunction and failure of various organs like kidney, heart, eyes and nerves (Middha et al. 2011). The adverse effects of anti-diabetic drugs drifted scientific interest towards plant-based chemical moieties which, in turn, might reduce economic and clinical toll of DM (Singh et al. 2012; Palsamy and Subramanian 2008). It has also been proposed that decrease of lipid peroxidation and increased antioxidant would reduce diabetes disorders (Kiran et al. 2013; Prasad et al. 2012). The ethnobotanical lore of India is very rich. In India, numerous floras are used for the treatment of diabetes since ancient days and today scientific evidences also support their uses (Middha et al. 2009, 2016a).

Bambusa balcooa Roxb. (BB), (Poaceae) is an indigenous species native to India. The culms are tangled having a diameter of about $15 \mathrm{~cm}$ and attain a maximum height of about $18.3 \mathrm{~m}$. The tender shoots are edible (Goyal et al. 2010a). The siliceous secretion of the culm is believed to be aphrodisiac and can also be used as tonic (Manandhar 
and Manandhar 2002). In Dibrugarh district, Assam, India crushed leaves of BB combined with Cucumis sativus is administered orally to treat epitaxis (Kalita and Phukan 2010). Apart from this, BB young leaves decoction is consumed orally to treat diabetes traditionally by the Moran folk of Tinsukia district of Assam, India (Kalita and Phukan 2009). In vitro antidiabetic studies of BB have shown promising results (Middha and Usha 2012). Survey of scientific literature revealed that the experimental evidence on the traditional use of this plant is not yet documented. To the best of our knowledge, no compounds have been detected in BB until now. Keeping this in view, the present study might be the first one to evaluate the toxicity, anti-diabetic activity, in vitro and in vivo antioxidant activity of the leaf of $\mathrm{BB}$ and also identify active compounds by using HPLC.

\section{Materials and methods}

\section{Chemicals and reagents}

Ascorbic acid, 2,2-diphenyl-1-picryl-hydrazyl (DPPH), ferric chloride $\left(\mathrm{FeCl}_{3}\right)$, gallic acid (GA), quercetin, sodium nitrite $\left(\mathrm{NaNO}_{2}\right)$, trichloroacetic acid (TCA) were obtained from Himedia Laboratories Pvt. Ltd, Mumbai, India. acetic acid $\left(\mathrm{CH}_{3} \mathrm{COOH}\right)$, bromophenol blue, Di-potassium hydrogen phosphate $\left(\mathrm{K}_{2} \mathrm{HPO}_{4}\right)$, disodium hydrogen phosphate $\left(\mathrm{Na}_{2} \mathrm{HPO}_{4}\right)$, methanol, $n$-butanol, potassium di-hydrogen phosphate $\left(\mathrm{KH}_{2} \mathrm{PO}_{4}\right)$, potassium ferricyanide $\left(\mathrm{K}_{2} \mathrm{Fe}(\mathrm{CN}) 6\right)$, sodium hydroxide $(\mathrm{NaOH})$, sodium carbonate $\left(\mathrm{Na}_{2} \mathrm{CO}_{3}\right)$, hydrogen peroxide $\left(\mathrm{H}_{2} \mathrm{O}_{2}\right)$, ferrous sulfate, $\left(\mathrm{FeSO}_{4} \cdot 7 \mathrm{H}_{2} \mathrm{O}\right)$, pyridine $\left(\mathrm{C}_{5} \mathrm{H}_{5} \mathrm{~N}\right)$, ethanol $\left(\mathrm{C}_{2} \mathrm{H}_{5} \mathrm{OH}\right)$, and thiobarbituric acid were procured from Merck, Mumbai, India. Alloxan, 2,4-dinitro phenyl hydrazine, glutathione reductase, epinephrine, nicotinamide, pyridine, thiobarbituric acid, $t$-butyl hydrogen peroxide, reduced glutathione, adenine dinulcloetide phosphate, 1,1,3,3-tetra methoxy propane, Sigma (St. Louis, MO, USA). Insulin was obtained from Biocon Pvt. Lmt., Bangalore, India. All organic solvents were of spectral grade and general chemicals were of analytical grade and were purchased from local companies.

\section{Plant material and extraction}

The BB leaf was collected from Sukna forests during July, 2012. A voucher specimen has been deposited at Bambusetum, Kurseong Research Range, Sukna, Darjeeling, West Bengal (SUK/KRR/B005) (Goyal et al. 2012).

The material was shade dried and ground to fine powder. The pulverized leaves (10 g each) were extracted by Soxhlation using double-distilled water (BAQE), acetone
(BAE) and methanol (BME), respectively (Plant: solvent $1: 15 \mathrm{w} / \mathrm{v}$ ) (Middha et al. 2011) for $48 \mathrm{~h}$. Prior to use, the freeze-dried extracts were dissolved in double-distilled water (DDW) in desired concentrations for further use.

\section{Determination of plant extracts yield, total phenolic and flavonoid content}

The yield of evaporated extracts (w/w), the total soluble phenolic (mg gallic acid equivalent (GAE)/g) and flavonoid content (quercetin equivalents $(\mathrm{QE}) / \mathrm{g}$ ) in the extracts were estimated according to standard protocol of Goyal et al. (2010b).

\section{Determination of total flavonol content}

The protocol developed by Kumaran and Karunakaran (2007) was used to estimate the total flavonols using quercetin as a standard. The absorbance at $440 \mathrm{~nm}$ was read after $2.5 \mathrm{~h}$. The total amount of flavonol was calculated using previously formula used by Usha et al. 2014 and expressed as $\mu \mathrm{g}$ quercetin equivalents $(\mathrm{QE}) / \mathrm{g}$ of extract.

\section{Determination of total proanthocyanidin content}

The total proantocyanidin was determined as per protocol previously reported by Sun et al. (1998). Quercetin was used as standard. The absorbance was measured at $500 \mathrm{~nm}$. Total proanthocyanidin contents were expressed as $\mu \mathrm{g}$ quercetin equivalents $(\mathrm{QE}) / \mathrm{g}$ of extract, using the following equation of the curve: $Y=0.024 x-0.034, R^{2}=0.995$, where $x$ is the absorbance and $Y$ is the quercetin equivalent.

\section{In vitro antioxidant properties of the extract}

The antioxidant activity of the extracts and standard were assessed on the basis of the radical scavenging effect of the stable 2,2-diphenyl-1-picrylhydrazyl (DPPH) free radical, ferric reducing power assay (FRAP) and scavenging of hydrogen peroxide determined as described by Goyal et al. (2010b).

\section{Lipid peroxidation radical scavenging}

Inhibition of lipid peroxidation induced in rat whole liver homogenate

Lipid peroxidation was induced by $\mathrm{Fe}^{2+}$ EDTA system in the rat liver homogenate in the presence and absence of $\mathrm{BB}$ extracts to form thiobarbituric acid-reacting substance (TBARS). The TBARS thus formed was determined by the method of Ohkawa et al. (1979). 


\section{HPLC analysis of the aqueous extract of BB leaf}

\section{Preparation of standard and sample solutions}

Stock solutions of GA, Quercetin, $\beta$ sitosterol and Rutin were prepared at a concentration of $1000 \mu \mathrm{g} / \mathrm{ml}$ just prior to use and used as reference standards. The aqueous extract of BB leaf extract was dissolved in HPLC grade water to get the desired concentration of $4 \mathrm{mg} / \mathrm{ml}$ and used as sample. Prior to injection all the solutions were filtered through $0.22 \mu \mathrm{m}$ Millipore filter.

\section{Chromatographic conditions for HPLC}

The liquid chromatographic (isocratic HPLC Shimadzu) system consisted of pump (LC-10ATVP, Shimadzu, Japan), UV-Vis detector (SPD-10A Shimadzu) equipped with chromtech N2000 software and a Rheodyne (7725i) sample injector fitted with a $20-\mu l$ sample loop. The chromatographic separation was carried out on Supelco C18 (250X4.6 mm i.d. $5 \mu \mathrm{m}$ ) column. The mobile phase was water: methanol (60:40 v/v). All the separations were performed isocratically at a flow rate of $1 \mathrm{ml} / \mathrm{min}$ at room temperature. The peak area was determined using a UV detector at a wave length of $254 \mathrm{~nm}$. The chromatographic peaks of the analytes were confirmed by comparing their retention time $(\mathrm{Rt})$ and $\mathrm{UV}$ spectra with those of the reference standards. Integrated peak areas of the samples using the corresponding standard were used to quantify the compounds (Middha et al. 2013).

\section{In vivo hepatoprotective activity}

\section{Experimental animals}

Male Wistar albino rats (150-200 g) were housed under standard laboratory conditions of 12-h light and dark cycles, temperature of $25 \pm 2{ }^{\circ} \mathrm{C}$ and relative humidity of $60 \pm 1 \%$. The animals were given standard rat pellet (Lipton India Ltd., Bangalore) and tap water ad libitum. The experimental procedures were conducted after the approval of Ethical Committee (1368/ac/10/CPCSEA) and were in strict accordance with the protocol approved by Maharani Lakshmi Ammanni College Ethical Committee, Bangalore for the care and use of laboratory animals.

\section{Acute toxicity test}

Swiss albino mice (25-30 g) of either sex were divided into five groups of ten each. Animals were fasted overnight but water was made available prior to experiment. Aqueous extract of B. balcooa leaf at different dose levels [5.0, 6.0, $7.0,8.0,9.0 \mathrm{~g} / \mathrm{kg}$ body weight $(\mathrm{BW}) / \mathrm{ml}]$ was administered once to experimental groups. The mice were observed for $24 \mathrm{~h}$, mortality was recorded and median lethal dose $\mathrm{LD}_{50}$ (median lethal dose) was determined using the arithmetic method of Karber modified by Aliyu and Nwude (Middha et al. 2011) as per OECD guideline. The acute toxicity $\left(\mathrm{LD}_{50}\right)$ was calculated using the formula:

$$
\mathrm{LD}_{50}=\mathrm{LD} y-{ }^{I-r} \sum(\mathrm{Dd} \times \mathrm{Md}) / n \text {, }
$$

where LDy $=$ highest dose and $n=$ number of animals per group $(n=10)$, Dd $=$ dose difference, $\mathrm{Md}=$ mean dead.

\section{Alloxan-induced Wistar albino rat model for diabetes mellitus (DM)}

DM was induced in overnight-fasted rats by administering alloxan (2,4,5,6-tetraoxypyrimidine; 2,4,5,6- pyrimidinetetrone) $(150 \mathrm{mg} / \mathrm{kg} \mathrm{BW}$ i.p) in $50 \mathrm{mM}$ phosphate buffer ( $\mathrm{pH} 7.0$ ) in a volume of $1 \mathrm{ml} / \mathrm{kg} \mathrm{BW}$. Fasting blood glucose (FBG) with 220-260 dl/ml was considered diabetic and was used for further experimental purposes (Middha et al. 2011, 2012).

\section{Experimental groups}

Rats were randomly allotted into seven groups.

Group 1 served as normal control and received distilled water (NL).

Group 2 served as normal animals treated with $\mathrm{BB}$ $200 \mathrm{mg} / \mathrm{kg} \mathrm{BW}$ (NL + BB).

Group 3 served as diabetic control animals treated with alloxan (DC).

Group 4 served as alloxan-induced diabetic rats treated with $100 \mathrm{mg} / \mathrm{kg} \mathrm{BW}$ aqueous extract of BB leaf $(\mathrm{DC}+\mathrm{LB})$ for 45 days.

Group 5 served as alloxan-induced diabetic rats treated with $200 \mathrm{mg} / \mathrm{kg} \mathrm{BW}$ aqueous extract of BB leaf $(\mathrm{DC}+\mathrm{HB})$ for 45 days.

Group 6 served as alloxan-induced diabetic rats treated with glibenclamide (DG) $(600 \mu \mathrm{g} / \mathrm{kg}$ BW) for 45 days.

Group 7 served as alloxan-induced Diabetic rats treated with standard drug insulin (DC + I) (2 units/kg BW) (Insugen, Biocon) daily intraperitonally for 45 days.

The drug treatment was carried out every day morning with the help of 16 gauge ball-tipped feeding needle for a period of 6 weeks. FBG was determined after 1 st and 6 th week of drug treatment. However, BW was determined on everyday basis. After 6 weeks of drug treatment, rats were euthanized using $0.3 \mathrm{ml} / 100 \mathrm{~g}$ i/p Ketamine $(300 \mathrm{mg} / \mathrm{kg})+0.15 \mathrm{ml} / 100 \mathrm{~g}$ Xylazine (30 $\mathrm{mg} / \mathrm{kg}$ ) as recommended by Committee for the Purpose of Control and Supervision of Experiments on Animals (CPCSEA) and biochemical assays were performed with liver. 


\section{Estimation of blood glucose}

Blood samples were withdrawn by end tail vein cutting method from overnight-fasted animals and blood glucose level was determined using one-touch electronic glucometer ACU check (Apollo Pharmacy, Bangalore, India) (Middha et al. 2012).

\section{Preparation of tissue}

Liver tissue was prepared by the method used by Middha et al. 2011. The tissue was homogenized in $50 \mathrm{mM}$ phosphate buffer $\mathrm{pH}$ (7.0) containing $0.1 \mathrm{mM}$ EDTA to obtain a $5 \%$ homogenate for the malondialdehyde (MDA) tests. Analytical procedures for superoxide dismutase (SOD) and glutathione peroxidase (GPx) were assayed in the supernatant obtained after centrifugation of the $5 \%$ homogenate at $600 \times g$ for $10 \mathrm{~min}$ at $4{ }^{\circ} \mathrm{C}(\mathrm{RV} / \mathrm{FM}$, super spin, Plastocraft, India).

\section{Biochemical estimation}

Markers of lipid per oxidation (LPO), malondialdehyde (MDA), glutathione peroxidase (GPx) and the activities of superoxide dismutase (SOD) in liver tissue were determined as described by Middha et al. (2011).

\section{Statistical analysis}

Data were expressed as mean $\pm \mathrm{SE}$. Comparison between different groups was done using one-way ANOVA, followed by Tukey's Multiple comparison test's (Graph pad Prism windows 5). $p<0.05$ was considered to be statistically significant. All determinations were carried out in triplicates.

\section{Results and discussion}

\section{Plant yield}

The plant yield of different fractions of B. balcooa leaf, i.e. BAQE, BME and BAE was found to be 7.56, 6.97 and $5.73 \%$, respectively. The highest yield was obtained when extracted with water followed by methanol and acetone. Solvent selection was done based on the ethnopharmacological uses of the plants. Previous studies indicate methanol, water and acetone extraction as the most popular solvents used for the plant extraction research (Middha et al. 2013, 2014, 2016a, b; Goyal et al. 2011a, b, 2013).
Total phenolic, flavonoid, flavonol, proanthocyanidin contents

It was elucidated that the BME showed higher phenolic content than the BAQE and BAE in $\mathrm{mg} / \mathrm{g}$ as GA equivalent, i.e. BME $(378.55 \pm 0.03)>\operatorname{BAQE}(367.90 \pm 0.016)$ $>$ BAE (219.96 \pm 0.026$)$. BME also exhibited high content of flavonoid, flavonol and proanthocyanidin (Table 1). The higher polyphenolic content in BME might be due to the difference in the polarity of the solvent and the potential of methanol was to release the bound polyphenols present in the cell wall of the plants (Goyal et al. 2011a, b). Thus, methanol proved to be a suitable solvent for extraction of the plant as our studies are in accordance to the solvent used for various plants with previous reports (Middha et al. 2013, 2016a, b).

\section{In vitro antioxidant assays}

\section{DPPH radical scavenging activity}

The radical scavenging activity, using a DPPH-generated radical, was tested with different sample extracts (Fig. 1). It was observed that the BME exhibited the highest radical scavenging activity followed by BAQE. However, BAE extract showed the weakest activity.

\section{Ferric reducing power assay (FRAP)}

The reducing power of the extract was also found to be substantial. The reducing power in different leaf extracts of $\mathrm{BB}$ ranged from 0.006 to 0.217 at concentrations ranging from 20 to $200 \mu \mathrm{g} / \mathrm{ml}$. The reducing capacity of extracts was as follows: $\mathrm{BAQE}>\mathrm{BME}>\mathrm{BAE}$ (Fig. 2). In the case of reducing power assay, the transformation of $\mathrm{Fe}^{3+}$ to $\mathrm{Fe}^{2+}$ in the presence of either the extract or the standard (ascorbic acid) is a measure of reducing capability. It is found that the reducing power of the extract increases with increase in concentration. The highest reducing ability was noted in BAQE (0.217) followed by BME (0.079) and BAE (0.027) compared to ascorbic acid (0.041) as standard at the concentration of $200 \mu \mathrm{g} / \mathrm{ml}$. Similar trend shown by the BAE and BME was very similar at 20,80 and $120 \mu \mathrm{g} / \mathrm{ml}$. Results were in accordance to previous works on other bamboo species (Goyal et al. 2011a; Nagavani and Rao 2010). Mostly, the antioxidant activity in plants is due to the presence of polyphenols (Nakbi et al. 2010; Middha et al. 2013; Usha et al. 2014). Moreover, the higher the inhibitory action, the more powerful is the antioxidant activity (Ajith 2010). 
Table 1 Polyphenol contents in different fractions of B. balcooa leaf $(n=3, X \pm$ SEM)

\begin{tabular}{lrrr}
\hline & \multicolumn{1}{c}{ BAQE } & \multicolumn{1}{c}{ BME } & \multicolumn{1}{c}{ BAE } \\
\hline TPC $^{\text {a }}$ & $367.90 \pm 0.016$ & $378.55 \pm 0.030$ & $219.96 \pm 0.026$ \\
TFC $^{\text {b }}$ & $355.20 \pm 0.014$ & $365.20 \pm 0.034$ & $227.20 \pm 0.007$ \\
TFLC $^{\text {c }}$ & $3.62 \pm 0.002$ & $12.30 \pm 0.006$ & $1.80 \pm 0.001$ \\
TPrC $^{\text {d }}$ & $38.44 \pm 0.010$ & $298.24 \pm 0.010$ & $20.39 \pm 0.009$ \\
\hline
\end{tabular}

a Total phenol content analyzed as gallic acid equivalent (GAE) $\mathrm{mg} / \mathrm{g}$ of extract

b Total flavonoid content analyzed as quercetin equivalent $(\mathrm{QE}) \mathrm{mg} / \mathrm{g}$ of extract

c Total flavonol content analyzed as quercetin equivalent (QE) $\mu \mathrm{g} / \mathrm{g}$ of extract

${ }^{d}$ Total proanthocyanidin content analyzed as cathechin equivalent $\mu \mathrm{g} / \mathrm{g}$ of extract

Fig. 1 DPPH scavenging activity of $B$. balcooa leaf extract compared to standard ascorbic acid

Fig. 2 Ferric reducing power assay of $B$. balcooa leaf extract compared to standard ascorbic acid
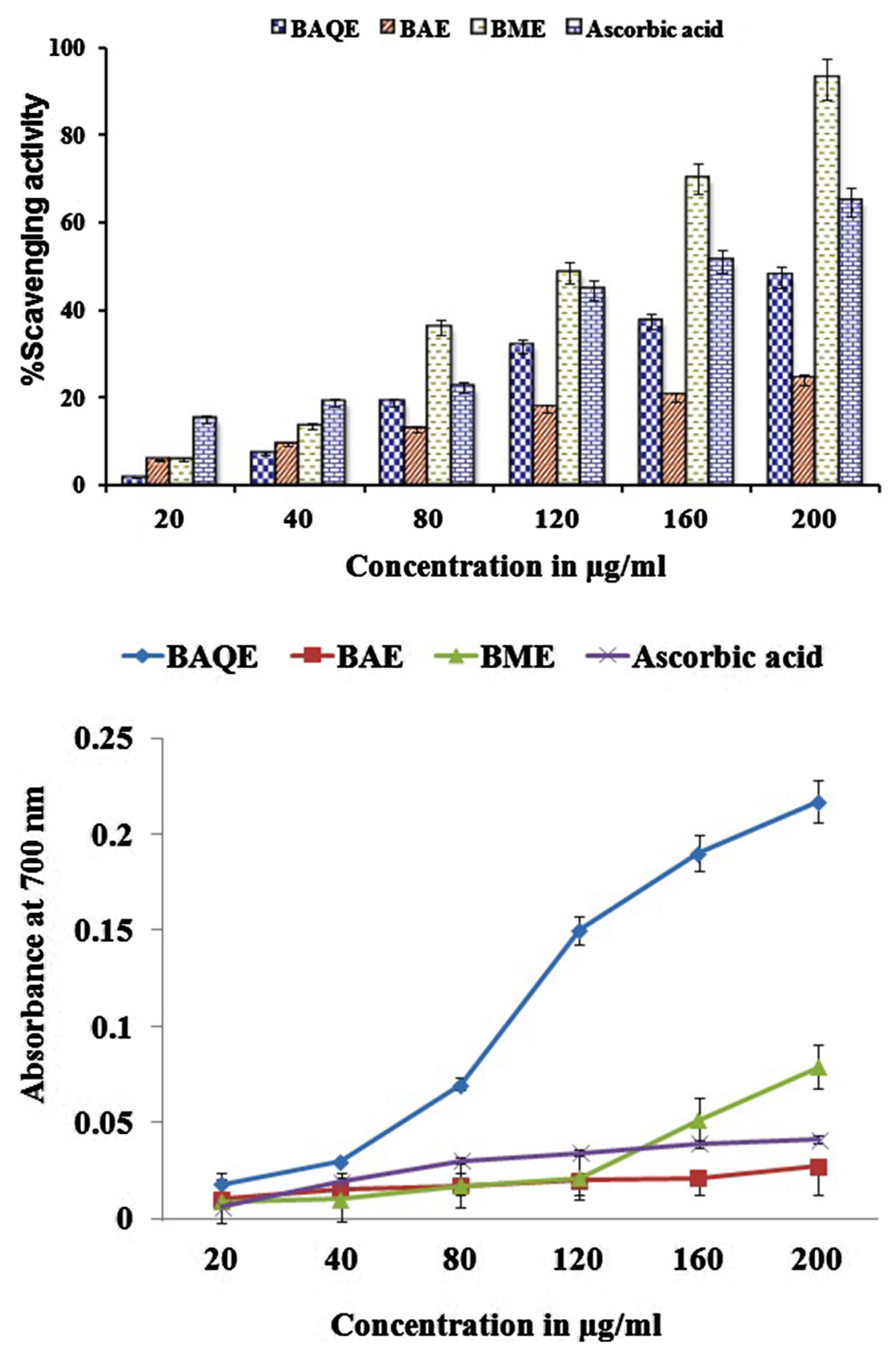

Concentration in $\mu \mathrm{g} / \mathrm{ml}$ 
Fig. 3 Hydrogen peroxide scavenging activity of $B$. balcooa leaf extract compared to standard ascorbic acid $\square$ BAQE $\square$ BAE $\square$ BME $\square$ Ascorbic acid

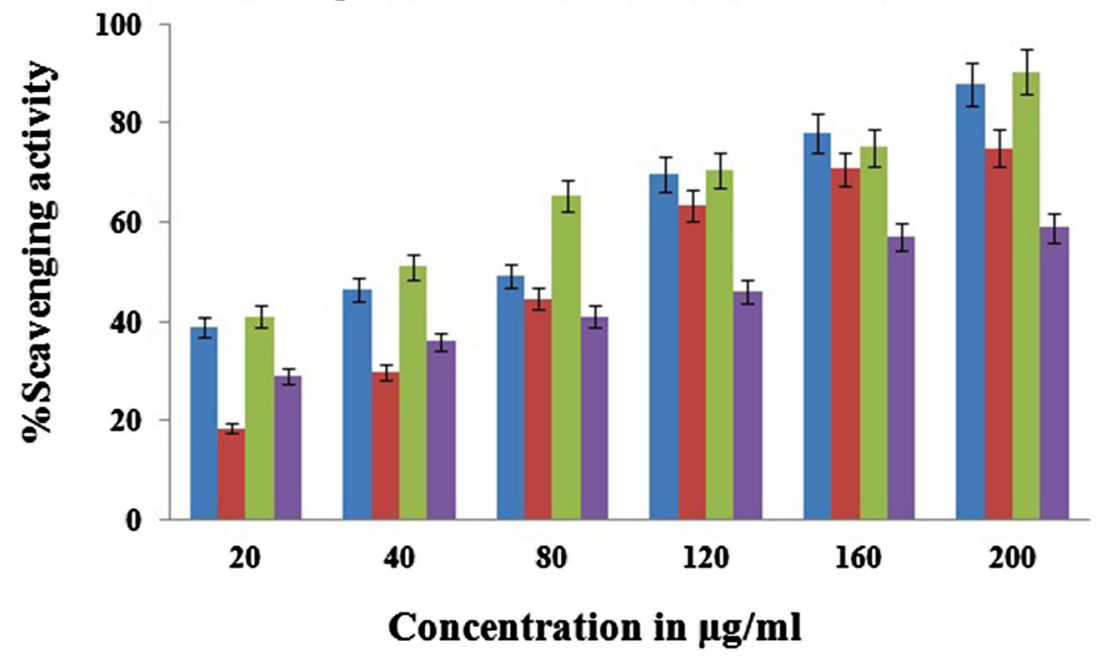

Hydrogen peroxide $\left(\mathrm{H}_{2} \mathrm{O}_{2}\right)$ scavenging activity

Figure 3 represents the $\mathrm{H}_{2} \mathrm{O}_{2}$ scavenging activity of BME, BAQE and BAE. A high amount of $\mathrm{H}_{2} \mathrm{O}_{2}$ scavenging activity was observed. The conversion of $\mathrm{H}_{2} \mathrm{O}_{2}$ into water may occur according to the antioxidant compounds as the antioxidant component present in the extract are good electron donors, they may accelerate the conversion of $\mathrm{H}_{2} \mathrm{O}_{2}$ to $\mathrm{H}_{2} \mathrm{O} . \mathrm{H}_{2} \mathrm{O}_{2}$ although being a weak oxidizing agent has the potential to turn off a few enzymes directly (Middha et al. 2013). In the presence of redox active transition metals $\mathrm{Fe}^{2+}$ and $\mathrm{Cu}^{2+}, \mathrm{H}_{2} \mathrm{O}_{2}$ is transformed to hydroxyl radical which might be the key to its toxic effect (Goyal et al. 2011a). Thus, the amount of $\mathrm{H}_{2} \mathrm{O}_{2}$ accrued in the cells should be monitored. Figure 3 illustrates the leaf extract is a good scavenger of $\mathrm{H}_{2} \mathrm{O}_{2}$.

\section{Lipid peroxidation assay}

Lipid peroxidation assay was used to access the antioxidant properties of the extracts in this study. The effects of various concentrations of $\mathrm{BAQE}, \mathrm{BME}$ and $\mathrm{BAE}$ $(10-80 \mathrm{mg} / \mathrm{ml})$ on lipid peroxidation are depicted in Table 2. As indicated in the study, BME could inhibit lipid

Table 2 Lipid peroxidation profile of $B$. balcooa different leaf extract $(n=3, X \pm$ SEM)

\begin{tabular}{llll}
\hline \multicolumn{4}{l}{ Lipid peroxidation $(I \%)$} \\
\hline Concentration $(\mathrm{mg} / \mathrm{ml})$ & \multicolumn{1}{l}{ BAQE } & \multicolumn{1}{l}{ BME } & \multicolumn{1}{l}{ BAE } \\
\hline Control & $00.00 \pm 0.00$ & $00.00 \pm 0.00$ & $00.00 \pm 0.00$ \\
10 & $7.72 \pm 0.70$ & $28.38 \pm 1.21$ & $22.60 \pm 0.34$ \\
20 & $10.27 \pm 0.91$ & $36.06 \pm 2.12$ & $37.41 \pm 1.44$ \\
30 & $27.21 \pm 1.45$ & $39.17 \pm 3.34$ & $44.96 \pm 1.07$ \\
40 & $28.21 \pm 2.41$ & $65.31 \pm 5.15$ & $55.08 \pm 1.22$ \\
80 & $36.26 \pm 1.32$ & $71.10 \pm 4.53$ & $68.74 \pm 3.11$ \\
\hline
\end{tabular}

peroxidation effectively than that of control followed by BAE and BAQE. The lipid peroxidation inhibition increased with increasing concentrations of all the three extracts. BME effectively and dose dependently protected the lipid peroxidation in the liver homogenate. So, it can be inferred that due to high contents of antioxidants in BME, it showed high antioxidant activity on lipid peroxidation.

\section{HPLC analysis of BAQE leaf extract}

In the present study, only the aqueous extract of BB leaf was considered for HPLC analysis primarily due to two reasons. One being the presence of moderate amount of antioxidants and the other being its traditional use to treat diabetes as aqueous extract by the Moran folk in Tinsukia district of Assam (India) (Kalita and Phukan 2010) in the same form. The chromatogram tested at $254 \mathrm{~nm}$ is depicted in Fig. 4. The HPLC estimation of BAQE leaf showed the presence of different phytoconstituents. However, the only three phytoconstituents or biomarkers were identified viz. rutin $(1.03 \mathrm{mg})$, gallic acid $(0.007 \mathrm{mg})$ and $\beta$ sitosterol $(0.065 \mathrm{mg})$ (Fig. 4). Rutin is the glycosidic form of quercetin. The pharmacological effect of rutin is well documented for antidiabetic conditions (Middha et al. 2013; Sharma et al. 2013). The presence of rutin in the bamboo extract can induce the $\beta$ cells to produce insulin and/or protect the $\beta$ cells from deterioration and, thus, help in reducing diabetes. Similarly, the antioxidant property of gallic acid is also reported (Ow and Stupens 2003) and the property of gallic acid to enhance the insulin receptor sensitivity might be the reason for its anti-hyperglycaemic activity (Huang et al. 2005). Moreover, rutin was higher in content compared to gallic acid and hence rutin may be responsible for the antidiabetic activity and the gallic acid, in turn, may act as adjuvant with rutin and enhance the pharmacological action of BB leaf extract. The third compound 


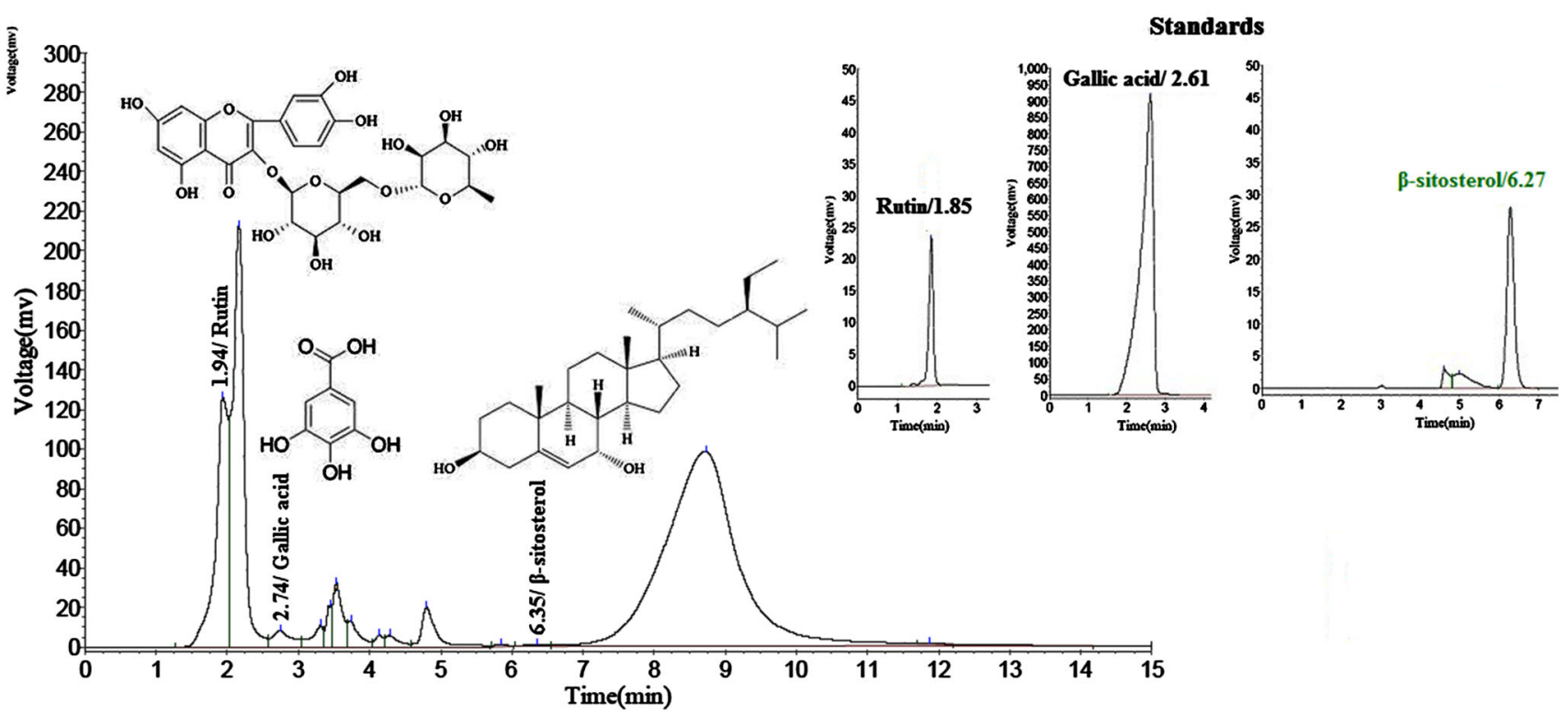

Fig. 4 HPLC chromatogram of B. balcooa aqueous leaf extract

detected is the $\beta$ sitosterol, which is already established as an active phytosterol having multiple pharmacological properties (Mutai et al. 2009). The presence of $\beta$ sitosterol in the plant extract might also complement for the antidiabetic activity of BB leaf extract. The possible reason might be that it elevates insulin secretion either through its antioxidant activity (Vivancos and Juan 2005) or regeneration of $\beta$ cells of Islets of Langerhans (Gupta et al. 2012).

\section{In vivo anti-hyperglycemic activity}

Here, an attempt was made to study the anti-hyperglycemic effect of the aqueous leaf extract of Bambusa balcooa in alloxan-induced diabetic rats.

\section{Acute toxicity test}

The primary sign of toxicity was noticed only after 10-12 $\mathrm{h}$ of the administration of extract with decrease in locomotor activity and the sense of touch. This was followed by reduced feed intake and prostration $5.18 \mathrm{~g} / \mathrm{kg}$ body after about $18 \mathrm{~h} . \mathrm{LD}_{50}$ of the aqueous extract of $\mathrm{BB}$ was found to be weight in mice and thus can be considered to be relatively safe as per Loomis and Hayes $\mathrm{LD}_{50}$ Scale (1996). In general, the lesser the $\mathrm{LD}_{50}$ value, the more lethal the compound is.

\section{Effect on fasting blood glucose, plasma insulin and glycated hemoglobin}

Table 3 infers the fasting blood glucose (FBG), plasma insulin and glycated hemoglobin (glycated $\mathrm{Hb}$ ) level in alloxan- induced diabetic rats treated with 100 and $200 \mathrm{mg} / \mathrm{kg}$ of BAQE extract, insulin, glibenclamide and control groups. FBG increased up to three folds after alloxan induction compared to normal control rats. The higher dose $(200 \mathrm{mg} / \mathrm{kg}$ $\mathrm{BW})$ of BAQE showed more significant reduction (50.86\%) in FBG than lower dose (100 mg/kg BW) (35.64\%) of extract and glibenclamide-treated rats $(44.98 \%)$ as compared to the diabetic control rats. The possible mechanism by which BAQE brings about its hypogycemic action might be that it possess insulin-like effect either by promoting glucose uptake or inhibiting hepatic gluconeogenesis (Tanko et al. 2008) also it might act by eliciting either the pancreatic secretion of insulin from the $\beta$ cells of Islets of Langerhans or its release from the bound form (Middha et al. 2012). Similar to FBG level, the administration of extract at 100 and $200 \mathrm{mg} / \mathrm{kg} \mathrm{BW}$ and glibenclamide significantly reduced the glycated $\mathrm{Hb}$ level by $34.81,54.27$ and $40.78 \%$ as compared to diabetic control rats. This decrease in the glycated $\mathrm{Hb}$ level might be due to increase in insulin secretion and reactivation of glycogen synthase enzyme system (Pandhare et al. 2011). The infusion of BAQE extract at both the doses significantly increased the plasma insulin level from $2.09 \pm 0.27 \mu \mathrm{U} / \mathrm{ml}$ in diabetic control to $7.08 \pm 0.41$ and $11.08 \pm 0.54 \mu \mathrm{U} / \mathrm{ml}$ at 100 and $200 \mathrm{mg} / \mathrm{kg} \mathrm{BW}$, respectively. These observations suggest that the hypoglycaemic activity of this bamboo may be mediated through enhancement of peripheral metabolism of glucose and an increase in insulin release.

\section{Effect of BAQE leaf extract on SOD, GPx and MDA}

In the current study, the activity of endogenous enzymatic antioxidants such as SOD and GPx has been evaluated. 
Table 3 Effect of B. balcooa aqueous leaf extract on fasting blood glucose, plasma insulin and glycated Hb levels in control and alloxaninduced diabetic rats

\begin{tabular}{lccc}
\hline Experimental groups & Fasting blood glucose $(\mathrm{mg} / \mathrm{dL})$ & Plasma insulin $(\mu \mathrm{U} / \mathrm{ml})$ & Glycated Hb $(\%$ total $\mathrm{Hb})$ \\
\hline $\mathrm{NL}$ & $89.54 \pm 6.74$ & $13.15 \pm 0.65$ & $1.32 \pm 0.07$ \\
$\mathrm{NL}+\mathrm{BB}$ & $90.12 \pm 8.87$ & $13.09 \pm 1.71$ & $1.28 \pm 0.21$ \\
$\mathrm{DC}$ & $289 \pm 3.87^{\mathrm{a}}$ & $2.09 \pm 0.27^{\mathrm{a}}$ & $5.86 \pm 0.74^{\mathrm{a}}$ \\
$\mathrm{LB}$ & $186.61 \pm 8.7^{\mathrm{b}}$ & $7.08 \pm 0.41^{\mathrm{b}}$ & $3.82 \pm 0.27^{\mathrm{b}}$ \\
$\mathrm{HB}$ & $142.86 \pm 7.17^{\mathrm{b}}$ & $11.08 \pm 0.54^{\mathrm{b}}$ & $2.68 \pm 0.42^{\mathrm{b}}$ \\
DG & $159.0 \pm 9.47^{\mathrm{b}}$ & $9.83 \pm 0.47^{\mathrm{b}}$ & $3.47 \pm 0.54^{\mathrm{b}}$ \\
DI & $108.60 \pm 1.43^{\mathrm{b}}$ & $12.08 \pm 0.46^{\mathrm{b}}$ & $1.98 \pm 0.42^{\mathrm{b}}$ \\
\hline
\end{tabular}

$N L$ normal, $N L+B B$ normal control rats treated with Bambusa balcooa leaf, $D C$ diabetic control, $L B$ diabetic control rats treated with $B$. balcooa leaf $(100 \mathrm{mg} / \mathrm{kg} \mathrm{BW}), H B$ diabetic control rats treated with $B$. balcooa leaf $(200 \mathrm{mg} / \mathrm{kg} \mathrm{BW})$, DG diabetic control treated with glibenclamide, $D I$ diabetic insulin. Values are mean $\pm \mathrm{SE}(n=6$ animals/group $)$ in experimental animals

a Significant $(p<0.05)$ as compared to normal control rats

b Significant $(p<0.05)$ as compared to allaxon induced diabetic rats

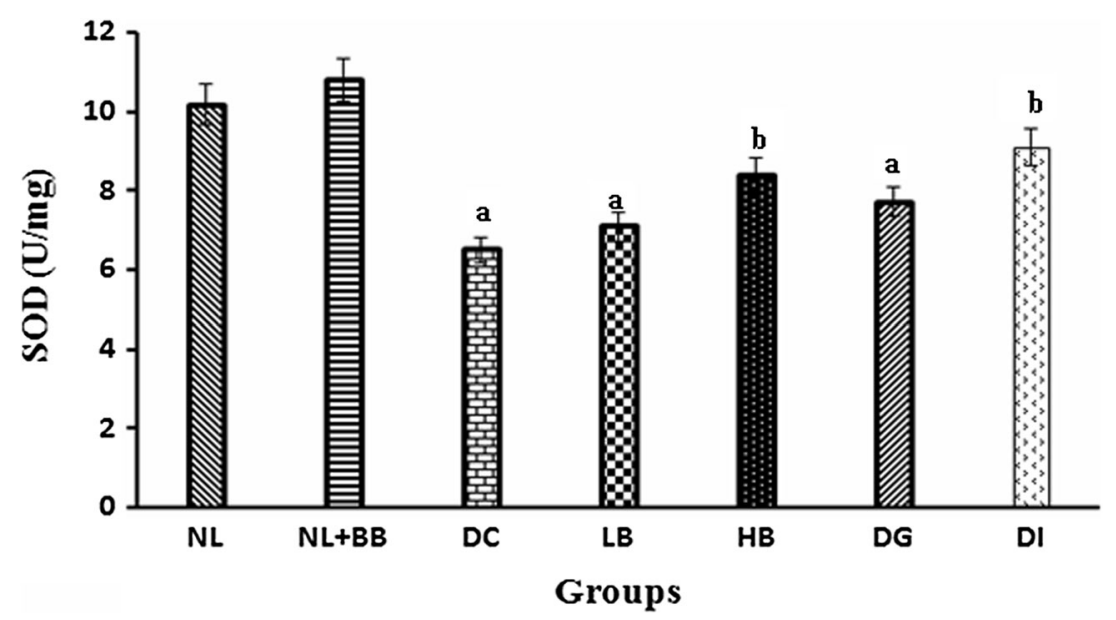

Fig. 5 Effect of B. balcooa leaf extracts (BB) supplementation on superoxide dismutase in liver of experimental rats. $N L$ normal, $N L+B B$ nomal + BB $(200 \mathrm{mg} / \mathrm{kg}$ b.w $), D C$ diabetic control, $D G$ diabetic glibenclamide, $D I$ diabetic insulin, $L B$ low BB $(100 \mathrm{mg} / \mathrm{kg}$

SOD is an important antioxidant defence enzyme which protects tissue against oxygen free radicals by catalyzing the dismutation of superoxide radicals converting it into hydrogen peroxide and molecular oxygen (Chis et al. 2009). The reactive oxygen species of SOD is more effective when its activity is followed by GPx. GPx is involved in detoxifying the hydrogen peroxide $\left(\mathrm{H}_{2} \mathrm{O}_{2}\right)$ generated by SOD (Halliwell 2012) and other organic hydroperoxides $(\mathrm{ROOH})$ and thus protects the membrane from lipid peroxidation.

In diabetic rats, the activity of SOD was significantly decreased in the liver as depicted in Fig. 5. Oral supplementation of $B$. balcooa leaf extract exhibited an increase in the SOD activity in the liver by 9.49 and $28.98 \%$ at a dose of 100 and $200 \mathrm{mg} / \mathrm{kg}$ BW. A similar trend was noticed in glibenclamide treated rats by $18.71 \%$. Similarly, b.w.), $H B$ high BB (200 mg/kg b.w). Values are means $+\mathrm{SE}(n=6$ animals/groups) in liver of experimental animals. Results were considered significant between the groups at $p<0.05$ in comparative studies with DC, those are not sharing the same letter $(\mathbf{a}, \mathbf{b})$

GPx activity was reduced in diabetic rats with respect to the control rats (Fig. 6). Treatment of diabetic rats with both low and high doses of extract up regulated the GPx activity by 9.96 and $16.06 \%$, respectively. Glibenclamidetreated rats also attained an elevation of $12.51 \%$ in GPx activity. In insulin treated rats, the activity was restored to normal. These observations emphasizes that the two enzymes are interconnected and lowering of their enzymatic activity leads to deposition of lipid peroxides which in turn increases the oxidative stress in the diabetic rats. Treatment with BAQE leaf extract increased the enzyme activity significantly and thus may help in eliminating the free radicals generated during diabetes mellitus.

The concentrations of MDA in liver of normal and experimental rats are depicted in Fig. 7. MDA is one of the final products of polyunsaturated fatty acid peroxidation 
Fig. 6 Effect of B. balcooa leaf extract (BB) supplementation on glutathione peroxidase in liver of experimental rats. $N L$ normal, $N L+B B$ nomal $+\mathrm{BB}$ (200 mg/kg b.w), $D C$ diabetic control, $D G$ diabetic glibenclamide, $D I$ diabetic insulin, $L B$ low BB $(100 \mathrm{mg} / \mathrm{kg}$ b.w.), $H B$ high $\mathrm{BB}(200 \mathrm{mg} / \mathrm{kg}$ b.w). Values are means $+\mathrm{SE}$ ( $n=6$ animals/groups) in liver of experimental animals. Results were considered significant between the groups at $p<0.05$ in comparative studies with DC, those are not sharing the same letter $(\mathbf{a}-\mathbf{c})$

Fig. 7 Effect of B. balcooa leaf extract (BB) supplementation on lipid peroxidation in liver of experimental rats. $N L$ normal, $N L+B B$ nomal $+\mathrm{BB}$ (200 mg/kg b.w), $D C$ diabetic control, $D G$ diabetic glibenclamide, $D I$ diabetic insulin, $L B$ low BB $(100 \mathrm{mg} / \mathrm{kg}$ b.w.), $H B$ high BB (200 mg/kg b.w). Values are means + SE ( $n=6$ animals/groups) in liver of experimental animals. Results were considered significant between the groups at $p<0.05$ in comparative studies with DC, those are not sharing the same letter $(\mathbf{a}, \mathbf{b})$
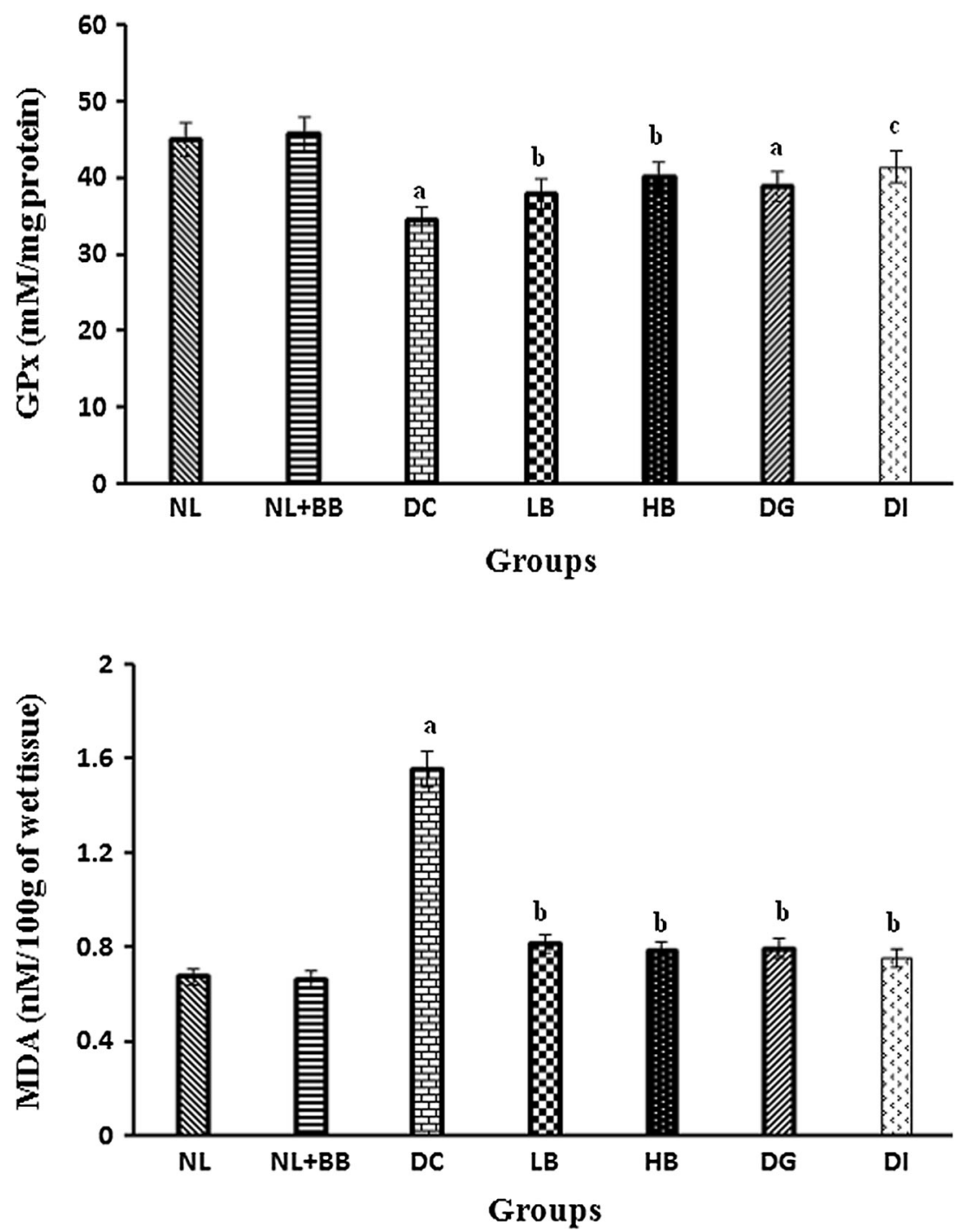

whose production increases with the increase in free radicals in the cells. MDA level is popularly designated as marker of oxidative stress (Gawel et al. 2004). In the present study, diabetic rats showed a significant increase in MDA compared to normal rats. Supplementation of LB extract lowered the lipid peroxidation by $47.44 \%$ whereas $49.36 \%$ reduction was observed in the rats fed with $\mathrm{HB}$ extract. The effect of glibenclamide treatment on MDA was in between the low and high dose and reduced MDA by $48.72 \%$. Thus, it can be inferred that this bamboo extract could be effective in reducing lipid peroxidation.

These results are in accordance with the other reports on the bamboo's activity. Nzreen et al. (2011) reported the hypoglycaemic activity of Bambusa arundinacea in streptozotocin induced diabetic rats. In their experiment, they found a significant decrease in the blood glucose level in treated rats along with reduction in the glutathione and lipid peroxidation level and thus elevation in the enzymes activity. In another experiment on Dendrocalamopsis oldhamii leaf extract, Lv et al. (2012) also observed significant decrease in the SOD and GPx activity in the liver when the animals were fed with the same. Their study suggested that the diabetic animals are exposed to oxidative stress and the leaf extract of B. balcooa can partially reduce the imbalances between the events of generation of reactive oxygen species and the scavenging enzyme activity. Thus, it can be inferred from the above study that BB could be a supplement as an antioxidant therapy due to its resemblance in activity with insulin and may prove to be beneficial in eliminating the hypergylcemia and preventing diabetic complications occurring due to lipid peroxidation and free radicals.

\section{Conclusion}

Thus, from the above analysis, it can be concluded that all the three compounds detected have the potential to treat diabetes individually and in this case they might

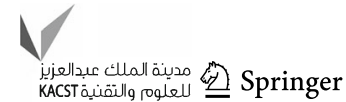


complement with each other and enhance the activity of $B$. balcooa to treat diabetes and thus justifies its traditional value by the ethnic communities in India to conserve good health. However, further studies on B. balcooa and its isolated compounds are essential, for better understanding the mechanism of action by which it modulates the oxidative stress in liver due to diabetes and thus develops a potential antidiabetic drug.

Acknowledgements The authors are grateful to Dr. T. L. Shantha (Director, MLACW) and Dr. Nagaveni MB. (Dean, Life Sciences), Department of Biotechnology, Maharani Lakshmi Ammanni College for Women for providing animal facilities. We would also like to thank Mr. Prasanta Kr. Ghosh, Range Officer, Kurseong Research Range, Sukna, Darjeeling for providing necessary help, support and information. The authors are also obliged to the bamboo taxonomist, Mr. P. P. Paudyal, Consultant, Bamboo Mission, Sikkim for helping in identifying the species of bamboo.

\section{Compliance with ethical standards}

Conflict of interest The authors declare no conflict of interest.

\section{References}

Ajith TA (2010) Ameliorating reactive oxygen species-induced in vitro lipid peroxidation in brain liver mitochondria and DNA damage by Zingiber officinale Roscoe. Indian J Clin Biochem 25:67-73

Chis IC, Ungureanu MI, Marton A, Simedrea R, Muresan A, Postescu ID, Decea N (2009) Antioxidant effects of a grape seed extract in a rat model of diabetes mellitus. Diabetes Vasc Dis Res 6(3):200-204

Choi SW, Benzie IF, Ma SW, Strain JJ, Hannigan BM (2008) Acute hyperglycemia and oxidative stress: direct cause and effect? Free Rad Biol Med 44(7):1217-1231

Gaweł S, Wardas M, Niedworok E, Wardas P (2004) Malondialdehyde (MDA) as a lipid peroxidation marker. WiadLek 57(9-10):453-455

Goyal AK, Middha SK, Usha T, Chatterjee S, Bothra AK, Nagaveni MB, Sen A (2010a) Bamboo-infoline: a database for North Bengal Bamboo's. Bioinformation 5(4):184-185

Goyal AK, Middha SK, Sen A (2010b) Evaluation of the DPPH radical scavenging activity total phenols and antioxidant activities in Indian wild Bambusa vulgaris "Vittata" methanolic leaf extract. J Nat Pharm 1(1):40-45

Goyal AK, Basistha BC, Sen A, Middha SK (2011a) Antioxidant profiling of Hippophae salicifolia growing in sacred forests of Sikkim, India. Funct Plant Biol 38:697-701

Goyal AK, Middha SK, Sen A (2011b) In vitro antioxidative profiling of different fractions of Dendrocalamus strictus (Roxb) Nees leaf extracts. Free Rad Antiox 1(2):42-48

Goyal AK, Ghosh PK, Dubey AK, Sen A (2012) Inventorying bamboo biodiversity of North Bengal: a case study. Int J Fund Appl Sci 1(1):5-8

Goyal AK, Mishra T, Bhattacharya M, Kar P, Sen A (2013) Evaluation of phytochemical constituents and antioxidant activity of some actinorhizal fruits growing in the forests of Northeast India. J Biosci 38(4):797-803

Gupta RK, Kumar D, Chaudhary AK, Maithani M, Singh R (2012) Antidiabetic activity of Passiflora incarnata Linn in streptozotocin-induced diabetes in mice. $\mathrm{J}$ Ethnopharmacol 139(3):801-806

Halliwell B (2012) Free radicals and antioxidants: updating a personal view. Nutr Rev 70(5):257-265

Huang TH, Peng G, Kota BP, Li GQ, Yamahara J, Roufogalis BD, Li $Y$ (2005) Anti-diabetic action of Punica granatum flower extract: activation of PPAR- $\gamma$ and identification of an active component. Toxicol Appl Pharm 207(2):160-169

Kalita D, Phukan B (2009) Folk medicines used by the Moran of Brahmaputra valley Tinsukia district Assam, India. Nat Prod Rad 8(1):73-76

Kalita D, Phukan B (2010) Some ethnomedicines used by the Tai Ahom of Dibrugarh district Assam India. Indian J Nat Prod Resour 1(4):507-511

Kiran B, Lalitha V, Raveesha KA (2013) Psoralea corylifolia L A potent medicinal plant with broad spectrum of medicinal properties. Int J Fund Appl Sci 2(1):20-22

Kumaran A, Karunakaran RJ (2007) In vitro antioxidant activities of methanol extracts of five Phyllanthus species from India. LWT Food Sci Technol 40:344-352

Loomis TA, Hayes AW (1996) Loomis's essentials of toxicology (ed) Academic Press, California, pp 208-245

Lv ZL, Lin X, Miao ZH, Guo HX, Wang JAH, Lei ML, Zhang BL (2012) Antioxidant activity of bamboo-leaf extracts from the species Dendrocalamopsis oldhamii. Sci Res Essays 7(44):3789-3796

Manandhar NP, Manandhar S (2002) Plants and people of Nepal. Timber Press, Portland, p 104

Middha SK, Usha T (2012) An in vitro new vista to identify hypoglycemic activity. Int J Fund Appl Sci 1(2):27-29

Middha SK, Mittal Y, Usha T, Kumar D, Srinivasan R, Vashisth L, Bhattacharjee B, Nagaveni MB (2009) Phyto-mellitus: a phytochemical database for diabetes. Bioinformation 4(2):78-79

Middha SK, Bhattacharjee B, Saini D, Baliga MS, Nagaveni MB, Usha T (2011) Protective role of Trigonella foenumgraceum extract against oxidative stress in hyperglycemic rats. Eur Rev Med Pharmacol Sci 15(4):427-435

Middha SK, Usha T, RaviKiran T (2012) Influence of Punica granatum $\mathrm{L}$ on region specific responses in rat brain during Alloxan-Induced diabetes. Asian Pac J Trop Biomed 2(2):S905S909

Middha SK, Usha T, Pande V (2013) HPLC evaluation of phenolic profile nutritive content and antioxidant capacity of extracts obtained from Punica granatum fruit peel. Adv Pharmacol Sci 2013:1-6 (Article id 296236)

Middha SK, Usha T, Pande V (2014) Pomegranate peel attenuates hyperglycemic effects of alloxan-induced diabetic rats. EXCLI J 13:223-224

Middha SK, Usha T, Pande V (2016a) Insights Into The causes and anti-hyperglycemic effects of Punica granatum rind in alloxaninduced diabetic rats. Chiang Mai J Sci 43:112-122

Middha SK, Usha T, Babu D, Misra Ak, Lokesh P, Goyal AK (2016b) Evaluation of antioxidative, analgesic and anti-inflammatory activities of methanolic extract of Myrica nagi leaves-an animal model approach. Symbiosis 70:179-184

Mutai C, Bii C, Vagias C, Abatis D, Roussis V (2009) Antimicrobial activity of Acacia mellifera extracts and lupanetriterpenes. J Ethnophamacol 123(1):143-148

Nagavani V, RaghavaRao T (2010) Evaluation of antioxidant potential and identification of polyphenols by RP-HPLC in Michelia champaca flowers. Adv Biol Res 4(3):159-168

Nakbi A, Tayeb W, Grissa A, Issaoui M, Dabbou S, Chargui I, Ellouz M, Miled A, Hammami M (2010) Effects of olive oil and its fractions on oxidative stress and the liver's fatty acid composition in 2,4dichlorophenoxyacetic acid-treated rats. Nutr Metab 7:80 
Nazreen S, Kaur G, MahboobAlam M, Haider S, Hamid H, Alam MS (2011) Hypoglysemic activity of Bambusa arudicea leaf ethanolic extract I streptozototoci induced diabetic rats. Pharmacologyonline 1:964-972

Ohkawa H, Ohishi N, Yagi K (1979) Assay for lipid peroxide in animal tissues by thiobarbituric acid reaction. Anal Biochem 95:351-358

Ow YY, Stupans I (2003) Gallic acid and gallic acid derivatives: effects on drug metabolizing enzymes. Curr Drug Metab 4(3):241-248

Palsamy P, Subramanian S (2008) Resveratrol a natural phytoalexin normalizes hyperglycemia in streptozotocin-nicotinamide induced experimental diabetic rats. Biomed Pharmacother 62:598-605

Pandhare RB, Sangameswaran B, Mohite PB, Khanage SG (2011) Antidiabetic activity of aqueous leaves extract of Sesbaniasesban (L) Merr in streptozotocin induced diabetic rats. Avicenna $\mathbf{J}$ Med Biotechnol 3(1):37-43

Prasad MP, Shekhar S, Amit B (2012) Phytochemical analysis and antioxidant potential of piper species and its molecular characterization by RAPD markers. Int J Fund Appl Sci 1:71-73
Sharma S, Ali A, Ali J, Sahni JK, Baboota S (2013) Rutin: therapeutic potential and recent advances in drug delivery. Expert Opin Investig Drugs 22(8):1063-1079

Singh R, Singh MK, Chandra LR, Bhat D, Arora MS, Nailwal T, Pande V (2012) In vitro antioxidant and free radical scavenging activity of Macrotyloma uniflorum (Gahat dal) from Kumauni region. Int J Fund Appl Sci 1(1):9-12

Sun JS, Tsuang YW, Chen IJ, Huang WC, Lu FJ (1998) An ultra weak chemiluminescence study on oxidative stress in rabbits following acute thermal injury. Burns 24:225-231

Tanko Y, Yerima M, Mahdi MA, Yaro AH, Musa KY, Mohammed A (2008) Hypoglycemic activity of methanolic stem bark of Adansonni adigitata extract on blood glucose levels of streptozocininduced diabetic wistar rats. Int J Appl Res Nat Prod 1(2):32-36

Usha T, Middha SK, Bhattacharya M, Lokesh P, Goyal AK (2014) Rosmarinic acid a new polyphenol from Baccaurea ramiflora Lour leaf: a probable compound for its anti-inflammatory activity. Antioxidants 3(4):830-842

Vivancos M, Juan JM (2005) $\beta$-Sitosterol modulates antioxidant enzyme response in RAW 2647 macrophages. Free Rad Biol Med 39:91-97 